\title{
On the informativeness of the shock pulse method for controlling the geocomposite constructions strength
}

\author{
Liliia Prokhorets ${ }^{1, *}$ \\ ${ }^{1}$ Institute of Geotechnical Mechanics named by N. Poljakov of National Academy of Sciences of \\ Ukraine, 49005, Dnipro, Simferopolska Str., 2a, Ukraine
}

\begin{abstract}
This article shows the possibility of using the shock impulse method widely used in the building industry for the control of aboveground concrete structures in relation to elements of underground geocomposite protective constructions. As a result of experimental studies performed in the laboratory on various mortar mixtures that harden, it was established that there is a close correlation relationship between two data arrays: the values of the shock pulse duration and the uniaxial compression strength. The reliability of the obtained regression equations is in the range of $0.82-0.9$. This shows the possibility of using the shock pulse method in the new version, with the previously unused informative parameter - the shock pulse duration for assessing the strength of mortar mixes that harden, which are widely used to create geocomposite constructions.
\end{abstract}

\section{Introduction}

One of the promising ways to improve the sustainability of the workings located in a blockstructured environment is the directional change in the properties of the rock massif by creating geocomposite protective constructions. The effectiveness of this design is determined by the validity of the selected parameters and quality control of its construction, as well as monitoring the current state of the system "support - massif".

The creation of a geocomposite is achieved in various ways, for example, by injecting a solution that harden into the massif or by tamponage a mounting space, by cementation and concrete spraying, using bookmarks that harden, etc. One of such geocomposite construction's elements is always mortar mix that harden [1 - 3].

Cementation of fractured rock massif is a traditional technical solution to increase its carrying capacity. In this case, the matrix and the reinforcing element are similar in their physical and mechanical properties. The key to improving the stability of a block massif in unequal component stress field is the adhesion of the material being injected into the cracks. In Ukraine, studies on the cementation of the rock massif for the conditions of mining enterprises and the development of an appropriate regulatory and regularity technical base are carried out, including at the Institute of Geotechnical Mechanics named by N. Poljakov of National Academy of Sciences of Ukraine [4].

\footnotetext{
${ }^{*}$ Corresponding author: prohoreclv@gmail.com
} 
Under the category of geocomposite construction, the plot of the rock massif with tamponage also falls, since, in addition to filling the voids behind the enclosing shell, the cement slurry penetrates into the cracks between the blocks. Tamponage with the use of cement-based solutions is very effective for stabilizing the rock mass, both as an independent tool and in combination with others. Many organizations are engaged in research in the field of tamponage in Ukraine. A feature of the work performed at the Institute of Geotechnical Mechanics named by N. Poljakov of National Academy of Sciences of Ukraine is the study of the effect of various additives influence on the strength and waterproofing properties of tamponage slurry that harden.

One of the main ways to create geocomposite constructions with nonmetallic reinforcing elements is injection hardening of the geological environment. In addition to the classical schemes of hardening the massif with fastening mixtures, both on the basis of cement binders and on the basis of polymer resins, began to pay more attention to the possibility of using injection rock bolt. Initially, there were used in construction to strengthen the soil strata, but at the present time there are also used to increase the bearing capacity of a strongly disturbed rock massif. Injection rock bolts are perforated tubular structures with a transitional device for injecting cement mortar or a polymer-based binder. The use of support elements of this type provides not only the "stitching" of layers, as in metal-polymer rock bolts, but also the fastening of a chaotic block structure.

As follows from the above, a wide range of materials is currently used for the implementation of reinforcing elements of geocomposite structures: from metals to polymers.

Recently, in connection with the ever-increasing complexity of solving the problem of energy, interest in the development of uranium deposits has increased significantly. At the same time, due to the increase in the depth of development, the deterioration of mining and geological conditions for the development of uranium deposits, difficult economic circumstances for uranium mining enterprises and, consequently, an increase in production costs, the issue of substantiation and improvement of technologies for maintaining mine workings, support elements and control their condition.

\section{Methods}

The widespread use on underground uranium-mining enterprises of bookmarks that harden, the introduction of new high-adhesive binders, reinforced concrete and steelpolymer supports, the combination of which creates a geocomposite constructions with unique properties in the rock massif, with a simultaneous intensification of mining operations, put forward new, more stringent requirements for monitoring and diagnostics the state of the geomechanical system "massif - support and protective constructions." When reinforcing the rock massif with the use of geocomposite constructions, the need arises for the operational control of their condition. Preferable for rapid assessment of the current strength of material that harden directly at the place of its use are non-destructive testing methods. Ukraine has a national standard DSTU B V.2.7-220: 2009, which regulates the means and methods of non-destructive testing for concrete. For it, developed a number of methods and means of rapid assessment of strength characteristics. But due to the peculiarities of performing control in underground conditions, not all methods can be effectively used. At present, the shock pulse method $[5,6]$ is quite successfully used to control the strength properties of concrete.

The application of the method, however, has its own characteristics, which impede the direct transfer of the technique developed for the control of concrete structures in aboveground conditions in mine conditions. 
Therefore, the actual task is to adapt this methodological development to control the strength of hardening mixtures as elements of geocomposite protective - supporting constructions.

The author has developed a method and a means of assessing the strength of rocks and geocomposite constructions elements by the shock pulse method, which allows using it in underground conditions. This technique is based on the theoretically established correlation dependence of the ultimate strength for uniaxial compression and the shock pulse duration [7], which is expressed as follows:

$$
\tau \approx 2.95 \sqrt[5]{\frac{1}{V_{0}} \frac{m^{2}}{R}\left(\frac{1}{\rho_{1} C_{p 1}^{2}}+\frac{A^{2}}{\rho_{2}\left(\sigma_{c}+B\right)^{2}}\right)^{2}},
$$

where $\tau$ - the shock pulse duration, ms; $\rho_{1}$ and $\rho_{2}-$ the density of the hammer material and the material under test, respectively, $\mathrm{kg} / \mathrm{m}^{3} ; V_{0}$ - relative velocity of bodies at the initial moment of contact, $\mathrm{m} / \mathrm{s} ; R$ - the radius of the hammer's spherical surface, $\mathrm{m} ; m$ - the mass of the hammer, $\mathrm{kg}$; $C_{\mathrm{p} 1}$ - the speed of the longitudinal wave of the hammer material, $\mathrm{m} / \mathrm{s}$; $\sigma_{c}-$ ultimate strength for uniaxial compression, $\mathrm{MPa} ; A$ and $B-$ are constant values for a given test material.

This dependence is approximated as follows:

$$
\sigma_{c}=A \cdot \tau^{-B}
$$

It should be noted that the essence of the method is as follows: a hammer with spherical surface hits the surface of the object, and the entire impact energy (excluding heat losses) is expended on elastic and plastic deformations of the material under study. As a result of plastic deformations, a dint is formed, and elastic - a reactive force arises.

The higher the plastic properties of the medium, the more part of the impact energy is spent on plastic deformations, the duration of the impact increases and its strength properties decrease. Conversely, the higher the elastic properties, the magnitude of the force increases, the duration of the impact decreases which indicates an increase in strength of the material. That is, in the case of a normalized impact, the magnitude of the reactive force and the duration of the impact can serve as indicators of the object's strength investigation, to which the blow is struck. However, it is technically difficult to measure the strength and duration of the strike.

To measure these quantities, an electromechanical transducer is included in the design of the hammer, which converts the mechanical energy of an impact into an electrical impulse. Amplitude will be proportional to the force, and time is proportional to the duration of the impact. Therefore, amplitude and time can serve as indirect strength characteristics of concrete or rock.

\section{Results and discussion}

The author has conducted experimental studies of the dependence of the duration of a shock pulse on the strength properties of geomaterials and mortar mixes that harden. The studies were performed on samples of basic litotypes of rocks of the Zakhidnyi Donbas region (coal, sandstone, mudstone, siltstone), Artemivskyi gypsum deposits and Kryvyi Rih iron ore deposits, as well as the most widely used geocomposite materials in mining.

An important role in the formation of geocomposite constructions is played by various mixtures that harden. Therefore, mixtures based on cement binder were investigated in order to establish the informativeness of the method for monitoring the hardening dynamics 
of the mortar mixture. Also considered options with the addition to the base mixture of various additives: "Spraikon", calcium chloride $\mathrm{CaCl}_{2}$, "Tsentrament N3" (plasticizer), clay.

To strengthen the rocks, the most common is relatively cheap material - cement mortar. In most cases, portlandcement is used, and in the presence of aggressive groundwater, aggressive-resistant cements are used: pozzolanic, slag portlandcement and others. To control the properties of cement slurries (setting time, sedimentation stability, water permeability), activating additives are used: ferric chloride, calcium chloride, sodium silicate. Adding bentonite clay to the solution in the amount of $5 \%$ of the sand mass increases 3-4 times the sedimentation time of solid particles. Therefore, for tamponage the voids of the mounting space, it is advisable to use sands containing slurry inclusions to prepare the solution, which improves the pump ability of the mixture. However, a high content of clay in the solution (over $10 \%$ ) leads to a decrease in the strength of the cement stone.

In the work was used additive "Spraikon". This additive is based on portlandcement, reinforced with fibers and polymers and is designed to restore of the vertical and ceiling destroyed concrete. "Spraikon", mainly used for the restoration of concrete, is easily applicable to different types of cracks. Compressive strength after 28 days can reach $44 \mathrm{MPa}$. Also, for the preparation of the samples under study, we used an additiveplasticizer, a modified surfactant "Tsentrament N3". This additive significantly reduces the consumption of water in the concrete mix, increases its mobility, gives greater homogeneity of the concrete mix and improves its workability.

To determine the strength properties of geocomposites, mixtures based on cement binder were investigated. Samples in the form of cubes were formed from the studied mortar mixture. The mixture that harden was poured into molds and kept for 3 days. After which the tests was conduct.

At the next stage of the experiment, of the shock pulse duration of the tested samples from mixtures that harden was determined at various stages of their hardening. Then samples were tested for uniaxial compression using a PSU-10 press in accordance with GOST 21153.2 - 84. After processing the results for different categories of materials, a value field was obtained showing the dependence of the "shock pulse duration - uniaxial compression strength", and the regression equations were calculated.

The closest correlation between the strength characteristics and the duration of the shock pulse is observed for concrete. The possibility of estimating the strength properties of concrete using the proposed method was investigated. For testing, samples of hydrotechnical concrete were taken, from which samples of cubic shape with a $100 \mathrm{~mm}$ edge were made. The test results of hydraulic concrete are illustrated in Figure 1.

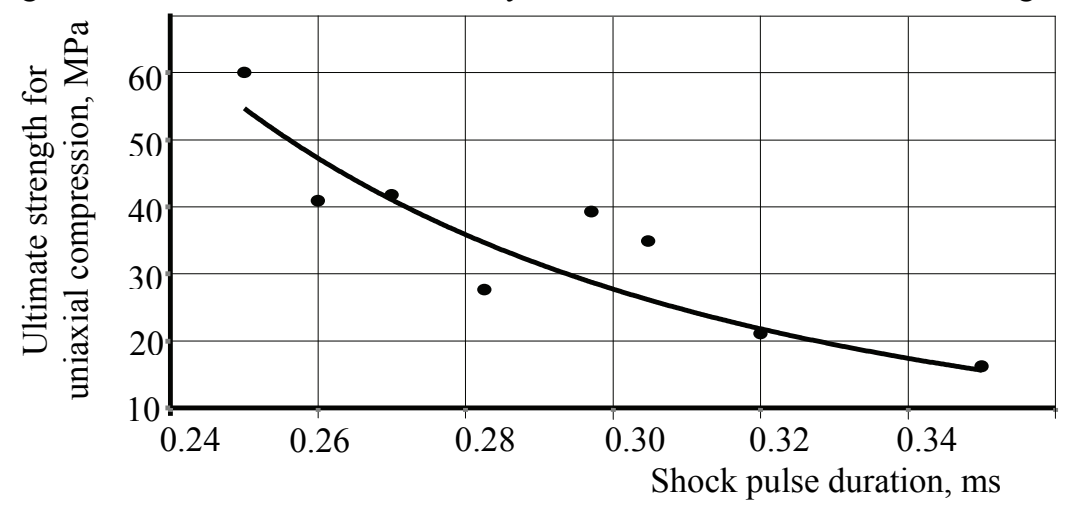

Fig. 1. Experimental relationship between the shock pulse duration and the ultimate strength for uniaxial compression for hydraulic concrete. 
The regression equation with a confidence of 0.9676 is:

$$
\sigma_{\mathrm{c}}=0.3119 \tau^{-3.7276}
$$

Unlike concrete, in the study of mixtures that harden was covered range with low values of strength. However, and in this case, the presence of a correlation between the strength and shock pulse duration was established, as illustrated in Figure 2 and Figure 3.

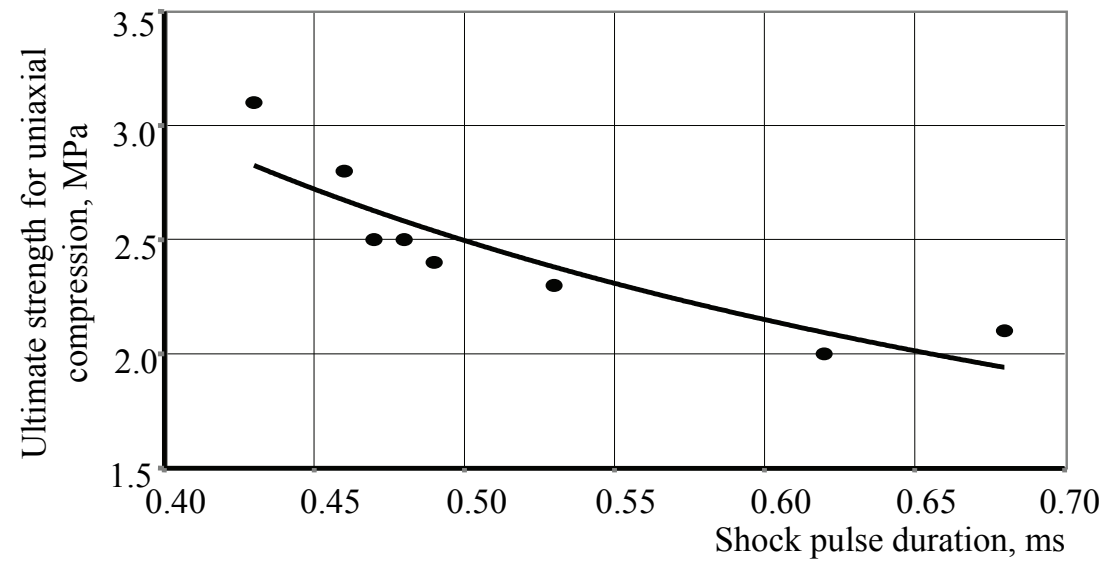

Fig. 2. Relationship between the shock pulse duration and the compressive strength for a water-sandcement mortar mixture that harden.

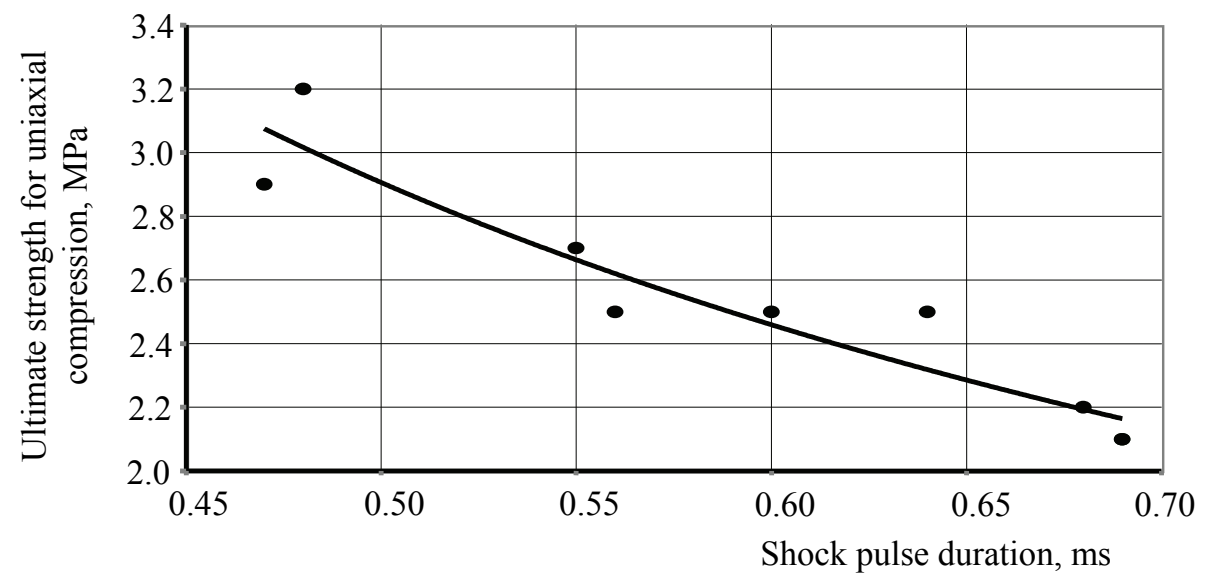

Fig. 3. Relationship between the shock pulse duration and the compressive strength for a water-sandcement mixture that harden with the additive of $\mathrm{CaCl}_{2}$.

The regression equations for arrays of data for mixtures that harden based on cement binder are presented in Table 1.

Table 1. Regression equations to describe the dependence of the strength for mixtures that harden based on cement on the shock pulse duration.

\begin{tabular}{|l|c|c|}
\hline \multicolumn{1}{|c|}{ Test mixture } & Regression equation & Equation reliability \\
\hline Water-cement-sand without additives & $\sigma_{\mathrm{c}}=1.4154 \tau^{-0.8189}$ & 0.8225 \\
\hline $\begin{array}{l}\text { Water-cement-sand with the additive } \\
\text { of calcium chloride }\end{array}$ & $\sigma_{\mathrm{c}}=1.5417 \tau^{-0.9147}$ & 0.8971 \\
\hline
\end{tabular}


The results are part of the program "Promoting the development of priority research areas" of state funding for the National Academy of Sciences of Ukraine (Code of program classification of expenses and crediting 6541230).

\section{Conclusions}

Thus, as a result of experimental studies performed in the laboratory on various mortar mixtures that harden, it was established that there is a close correlation relationship between two data arrays: the values of the shock pulse duration and the uniaxial compression strength. The reliability of the obtained regression equations is in the range of $0.82-0.9$. This shows the possibility of using the shock pulse method in the new version, with the previously unused informative parameter - the shock pulse duration for assessing the strength of mortar mixes that harden, which are widely used to create geocomposite constructions.

\section{References}

1. Musiyenko, S.P. (2012). To the development of technology and the construction of geocomposite security systems of mining. Geo-Technical Mechanics, 66, 113-119

2. Solodyankin, A.V., Kravchenko, K.V., Prokudin, A.Z., Vygodin A.M. (2016). Justification of rational parameters of the technology of tamponage mounting space. Visti Donetskogo girnychogo instytutu, 1, 22-29

3. Zubkov, A.A., Latkin, V.V., Neugomonov, S. S., Volkov, P.V. (2014). Perspective mounting methods of working in underground mines. Gornyy informatsionnoanaliticheskiy byulleten, (10), 106-116

4. Bulat, A. F. et al, (2011). Tekhnologichnyu reglament diagnostiki I vosstanovleniya zaglublennykh I podzemnykh sooruzheniy poverkhnostnogo kompleksa shakht na osnove sozdaniya geokompozitnykh konstruktsiy. Dnipropetrovsk: Monolit

5. Korevitskaya, M.G., Tukhtaev, B.Kh., Ivanov, S.I. (2013). The use of non-destructive methods for monitoring the strength of high-strength concrete. Promyshlennoe I grazhdanskoe stroitelstvo, 1, 53-54

6. Petrov, A.V., Phaskhutdinov, A.A., Khaziakhmetov, M.Ph., Yeremeeva, A.I. (2015). Features of the application of the shock pulse method in the study of the brickwork state of the buildings and structures in use. Ekspertiza promyshlennoy bezopasnosti I diagnostiki opasnykh proizvodstvennykh obyektov, 5, 170-171

7. Skipochka, S.I., Palamarchuk, T.A., Sergienko, V.N., Prokhorets, L.V. (2013). Rapid assessment of rocks strengthin the massif by the shock pulse method. Metallurgicheskaya I gornorudnaya promyshlennost, 2, 74-77 